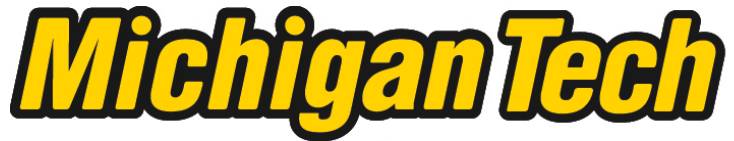 \\ Michigan Technological University Create the Future Digital Commons @ Michigan Tech
}

2010

Teaching and aligning upper level mathematics classes to Michigan high school content expectations in an alternative education setting: approaches and issues

Sarah Van Baale

Michigan Technological University

Follow this and additional works at: https://digitalcommons.mtu.edu/etds

Part of the Science and Mathematics Education Commons

Copyright 2010 Sarah Van Baale

Recommended Citation

Van Baale, Sarah, "Teaching and aligning upper level mathematics classes to Michigan high school content expectations in an alternative education setting : approaches and issues", Master's report, Michigan Technological University, 2010.

https://doi.org/10.37099/mtu.dc.etds/537

Follow this and additional works at: https://digitalcommons.mtu.edu/etds

Part of the Science and Mathematics Education Commons 


\title{
TEACHING AND ALIGNING UPPER LEVEL MATHEMATICS CLASSES TO MICHIGAN HIGH SCHOOL CONTENT EXPECTATIONS IN AN ALTERNATIVE EDUCATION SETTING: APPROACHES AND ISSUES
}

\author{
By \\ Sarah Van Baale \\ A REPORT \\ Submitted in partial fulfillment of the requirements for the degree of \\ MASTER OF SCIENCE \\ Applied Science Education
}

MICHIGAN TECHNOLOGICAL UNIVERSITY

2010

Copyright (C) Sarah Van Baale 2010 
This report, "Teaching and Aligning Upper Level Mathematics Classes to Michigan High School Content Expectations in an Alternative Education Setting: Approaches and Issues," is hereby approved in partial fulfillment of the requirements for the Degree of MASTER OF SCIENCE IN APPLIED SCIENCE EDUCATION.

Department of Cognitive and Learning Sciences

Signatures:

Advisor

Dr. Shari L. Stockero

Committee Member

Dr. Kedmon Hungwe

Committee Member

Dr. John Irwin

Department Chair

Dr. Bradley Baltensperger

Date 


\begin{abstract}
Teaching and Aligning Upper Level Mathematics Classes to Michigan High School Content Expectations in an Alternative Education Setting: Approaches and Issues
\end{abstract}

$$
\text { by }
$$

\title{
Sarah Van Baale
}

After teaching regular education secondary mathematics for seven years, I accepted a position in an alternative education high school. Over the next four years, the State of Michigan adopted new graduation requirements phasing in a mandate for all students to complete Geometry and Algebra 2 courses. Since many of my students were already struggling in Algebra 1, getting them through Geometry and Algebra 2 seemed like a daunting task. To better instruct my students, I wanted to know how other teachers in similar situations were addressing the new High School Content Expectations (HSCEs) in upper level mathematics. This study examines how thoroughly alternative education teachers in Michigan are addressing the HSCEs in their courses, what approaches they have found most effective, and what issues are preventing teachers and schools from successfully implementing the HSCEs.

Twenty-six alternative high school educators completed an online survey that included a variety of questions regarding school characteristics, curriculum alignment, implementation approaches and issues. Follow-up phone interviews were conducted with four of these participants. The survey responses were used to categorize schools as successful, unsuccessful, and neutral schools in terms of meeting the HSCEs. Responses 
from schools in each category were compared to identify common approaches and issues among them and to identify significant differences between school groups.

Data analysis showed that successful schools taught more of the HSCEs through a variety of instructional approaches, with an emphasis on varying the ways students learned the material. Individualized instruction was frequently mentioned by successful schools and was strikingly absent from unsuccessful school responses. The main obstacle to successful implementation of the HSCEs identified in the study was gaps in student knowledge. This caused pace of instruction to also be a significant issue. School representatives were fairly united against the belief that the Algebra 2 graduation requirement was appropriate for all alternative education students. Possible implications of these findings are discussed. 


\section{Acknowledgements}

I would like to thank my advisor and committee chair, Dr. Shari Stockero, for her superb guidance and encouragement throughout the research process. Without her persistent help and direction, this project would not have been possible.

I would also like to thank Dr. Kedmon Hungwe who originally encouraged me to pursue my graduate degree and who has conveyed great wisdom in the many courses he taught.

Finally I would like to thank my family, especially my husband and parents, who were extremely patient throughout this process, and who provided me with the support at home that I needed in order to complete this degree. Also to my children, who sacrificed their time and attention these past few months, I am very grateful. 


\section{Table of Contents}

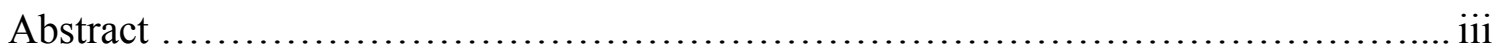

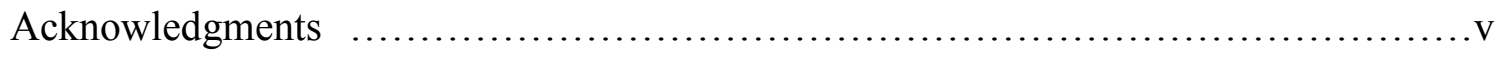

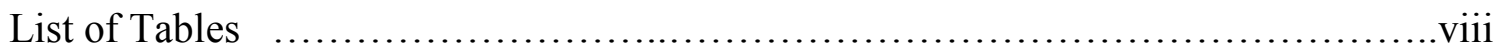

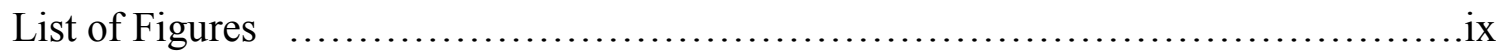

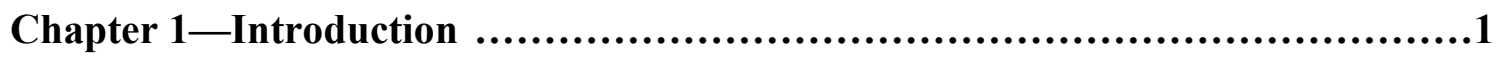

Chapter 2 - Literature Review .................................................5

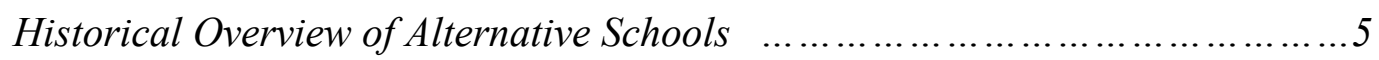

The Problem in Michigan .....................................................6

Possible Solutions $\quad$....................................................... 7

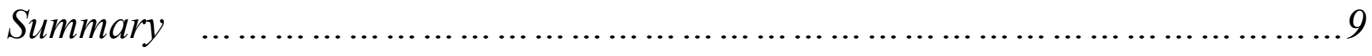

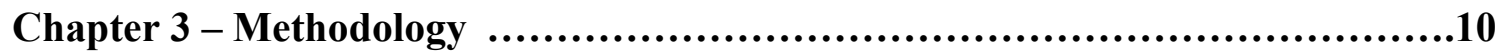

Participants ........................................................... 10

Data Collection .......................................................... 11

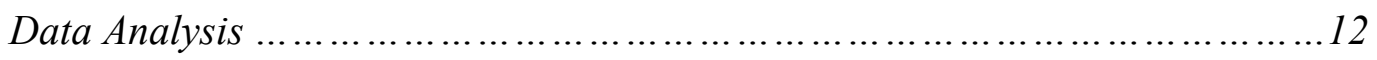

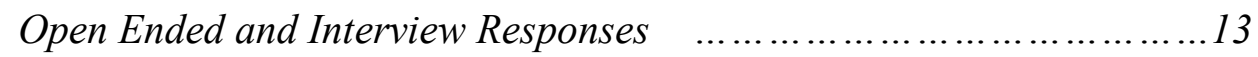

Classification of Schools ........................................... 15

Likert-scale Questions ............................................. 17

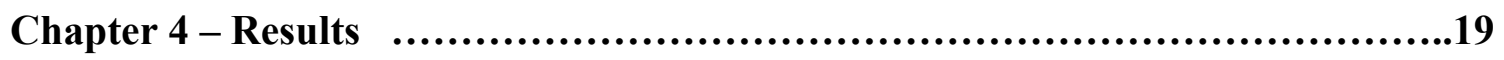

School Characteristics ...................................................22

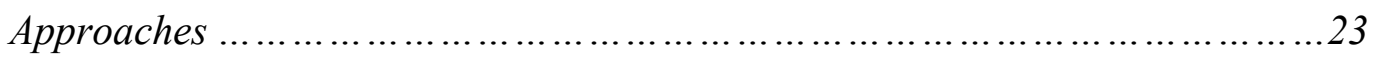

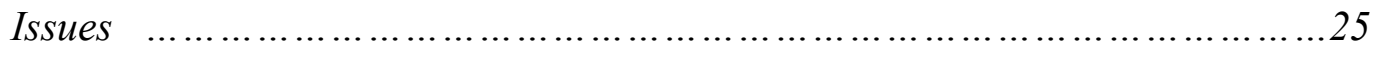

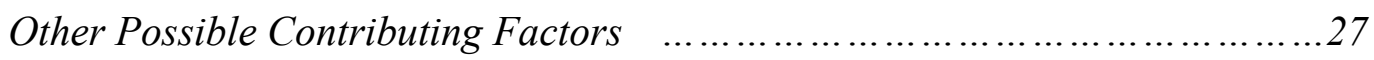


Chapter 5 -Discussion and Conclusion .........................................32

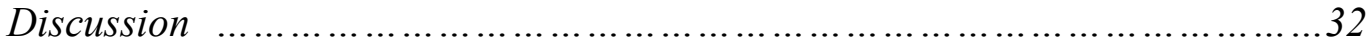

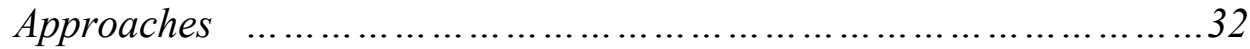

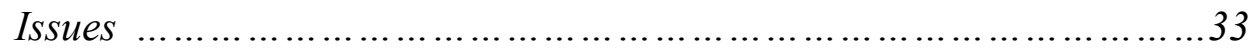

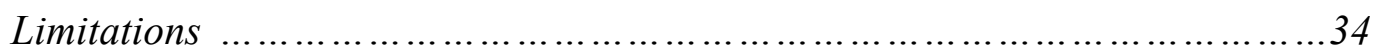

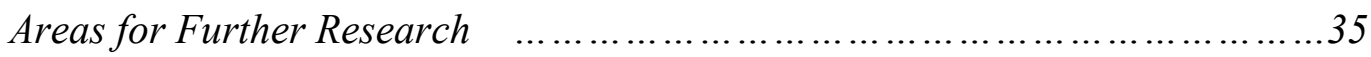

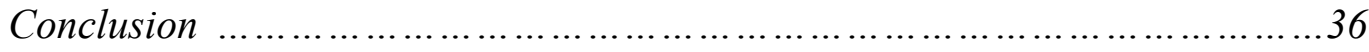

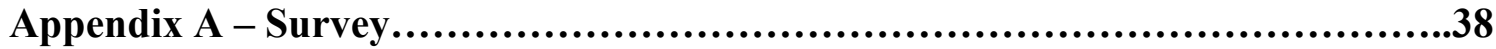

Appendix B - Approval Letter ....................................................41

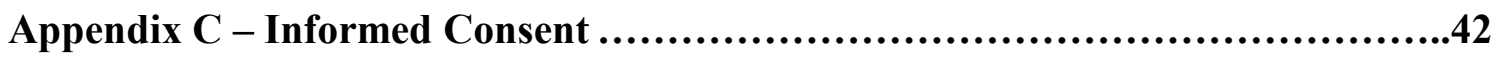

References...............................................................................44 


\section{List of Tables}

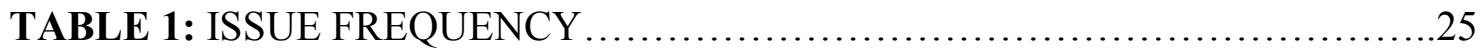

TABLE 2: AVERAGE RESPONSES TO QUESTIONS 8-16 AND QUESTION 18 BY SCHOOL CATEGORY ..........................................28 


\section{List of Figures}

FIGURE 1: CODING CATEGORIES AND SUB-CATEGORIES FOR

APPROACHES ....................................................... 14

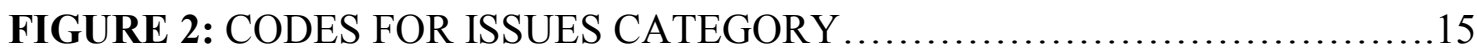

FIGURE 3: CATEGORY DESIGNATION FOR SCHOOLS .....................17

FIGURE 4: APPROACHES TABLE SUMMARIZED BY SCHOOL

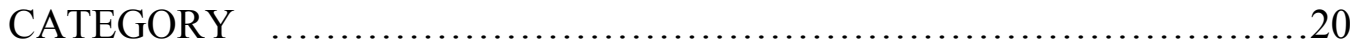

FIGURE 5: ISSUES TABLE SUMMARIZED BY SCHOOL CATEGORY..........21 


\section{Chapter 1 - Introduction}

Alternative education at the secondary school level is meant to be a second chance for students who have not found success in a regular high school environment. Often, class sizes are smaller, rules are a bit more lax, and the relationship between teacher and student is emphasized. Four years ago, I made a career change from teaching remedial freshman-level mathematics in a large school district to teaching all levels of mathematics at an alternative high school in a rural school district. At almost the same time, on April $20^{\text {th }}, 2006$, the State of Michigan adopted a new rigorous set of high school graduation requirements that required all students, even those in alternative education settings, to master mathematics through the Advanced Algebra level (Michigan Department of Education, 2006, p. 21).

When I began working in the alternative high school, the highest level of mathematics being taught was Pre-Algebra. There were no Algebra, Geometry, or Advanced Algebra books even available to me. To be fair, Business math was offered, which emphasized personal and basic company finance. Before the new state requirements, our school required students to earn two mathematics credits in order to graduate. When the new requirements were signed into law, our students were told they would need to earn at least four credits - one in Algebra, one in Geometry, one in Advanced Algebra, and another credit during their senior year in high school. The state allowed schools a few years to phase in the new requirements, but it seemed like a very daunting task since most of my students had little understanding of time, measurement, money, or even basic number sense. 
Over the course of the next two years, I managed to secure some used Algebra and Geometry books. In the 2007-2008 school year, my school began offering a two-year Algebra program in which about half of the students enrolled in the course passed. In the 2009-2010 school year, all students who had passed Algebra either at our school or at a previous high school were enrolled in a one-year regularly paced Geometry course. During that same time frame, the State of Michigan began to make some adjustments to the mathematics curriculum and made an allowance for certain students to substitute a Business mathematics class (or another mathematics related credit) in place of a half a year of an Advanced Algebra class (Michigan Department of Education, 2010, p.10). Our students qualified for this substitution and we are in the process of implementing our first Advanced Algebra class.

The process of changing our curriculum has not been as successful as we have hoped. Many of our students have such large gaps in mathematical understanding that learning Algebra, let alone Geometry, seems very far-fetched for them. The abstract concept of using a letter as a representation for a number is virtually impossible for students to comprehend when many do not have good number sense to begin with. Frustrated with the new mandate to push students through upper level mathematics, and finding little success in student mastery, I was curious to know how other alternative schools were addressing the upper level mathematics requirements in their classrooms.

Some of the more familiar ways of gleaning this type of information, such as professional development within districts, conferences, or even general teacher-to-teacher conversation are more difficult when the questions are specific to alternative education 
settings. Frequently in rural districts there is only one alternative high school in each county. The teachers at these schools rarely interact with other alternative teachers outside of their districts. Because the schools are small, often only one mathematics teacher is needed at each school and frequently funding is very limited. All of these factors make it more difficult for mathematics teacher collaboration in an alternative setting.

Given opportunities to work with regular education teachers, I picked their brains to see what types of changes they were making in their classrooms in order to better address the state requirements. Unfortunately, I found that few changes had been made except to make classes that were currently taught a requirement for all students. Also, I found that these teachers' daily challenges with student education were a bit different than mine. While all teachers face some similar challenges, the proportion of students who struggle with poor attendance (Wilkins, 2008), drug and alcohol abuse (Grunbaum et al., 2000), and lack of motivation (Alfassi, 2003) in an alternative setting is generally far greater than that of a regular education setting.

Concern about the success of our current mathematics program, and the need to better prepare our students for success in life, led me to conduct a study on Best Approaches to Teaching and Aligning Upper Level Mathematics Classes to Michigan HSCEs in an Alternative Education Setting. The questions to the study addressed were: 
1. What approaches are alternative schools using to implement Michigan's High School Content Expectations (HSCEs) in their upper level mathematics classrooms?

2. How thoroughly are the alternative high schools' mathematics curricula aligned with the HSCEs?

3. How successful do alternative school mathematics teachers perceive their approach to meeting the HSCEs has been? What issues may have hindered their success?

The following chapters will present an overview of other similar studies on this matter, as well as a summary of the data collected in this study. A detailed analysis of the data and what it might mean for other alternative schools in the state of Michigan is also addressed. 


\section{Chapter 2 - Literature Review}

\section{Historical Overview of Alternative Schools}

Alternative schools are a relatively new addition to the school system in the United States. They first appeared on the scene during the 1960's in the private sector and eventually made their way into the public realm during the 1970's (Raywid, 1998). According to Lange (1998) the definition of 'alternative' has been up for debate for many years. Schools labeling themselves as 'alternative' can refer to a variety of different types of settings. Schools of choice, charter schools, remedial programs, rehabilitation programs, and credit recovery programs all fall under the label of 'alternative.' For the purpose of this study, alternative programs are considered to be secondary schools that provide remedial programs and/or credit recovery. Juvenile facilities, rehabilitation programs, and adult education were not included.

Since the 1970's the number of alternative education schools has continually increased. However, in A National Survey of State Initiatives on Alternative Education, Katsyannis and Williams (1998) discovered that only 22 out of 38 responding states had even passed legislation addressing alternative education. Often states gave local school divisions the authority to establish their own policies and procedures for their individual programs. In fact, these researchers report that over $75 \%$ of responding states cited the key strength in their alternative education programs was local initiation and flexibility with state regulations that allowed them to meet the needs of their students. It was also 
noted that only 12 out of the 38 states had procedures in place to evaluate and monitor local programs.

\section{The Problem in Michigan}

Beginning in 2006, Michigan implemented a new set of standards for graduation that applies not only to general education high schools, but also to alternative high schools (Michigan Department of Education, 2006). The graduation guidelines not only specify what classes need to be completed in order to earn a diploma, but what content should be mastered in order to earn credit for those classes. Due to the rigid standards, many schools are struggling to find ways of fitting all the requirements into a student's standard 4-year high school career. This has been especially difficult for students who find themselves already behind with little time to catch up, as is the case for many students in alternative high schools. Guerin and Denti (1999) write, "To be effective, alternative education must adapt to the uniqueness of the setting, the transitory nature of the population, and the characteristics of the youth" ( $\mathrm{p} 76)$. Unfortunately, with so many rigid standards, flexibility and adaptations become more difficult to achieve. Thus, many alternative schools across the state of Michigan are questioning how to implement new state standards and graduation requirements into their current mathematics and science curriculum. Schools that haven't taught upper level mathematics and science classes in the past, are now struggling to find ways to effectively teach Advanced Algebra, Chemistry, or Physics to students who have been tagged as remedial. 


\section{Possible Solutions}

Schools in other states have been addressing similar problems in alternative school settings, with some level of success. Some schools, for example, have used admission policies to increase the level of success of their students. Cher Tufly, principal of Colorado's Finest Alternative High School in Englewood, Colorado, claims to have great success with graduation rates and describes some of the policies she implements in her article, An Alternative to Failure (Tufly, 2001). Tufly explains one of the policies her school implements is a prerequisite to enrollment that requires all students to take an achievement exam and score at least at a grade 6 level in mathematics and reading. Before they are awarded a diploma, students must achieve a grade 11 performance level. Since students are given until the age of 21 to meet this standard, this requires many of them to raise their performance by five grade levels in less than five years time. By filtering out some lower level students, graduation rates naturally increased.

While rigorous admission policies may be one way to raise performance levels, other schools tend to focus more on raising the motivation of students already within their walls. Finnan and Chasin (2007) claim that many alternative schools still have a lot of room for improvement when addressing students' motivational problems. However, Affiliated Alternatives out of Wisconsin, a school highlighted for their success with atrisk students, supports the learning of their low-achieving students by building on students' strengths, rather than focusing on their failures. The authors describe a curriculum that is often project based and includes reading, mathematics, and science connected to a specific project, "emphasizing the connection between school learning and 
real-life learning" (p. 627). Dicintio (1999) agrees with the idea that "Student control, challenging activities, personalization of content, and interactive teaching appear to be crucial aspects of [motivational] instruction for at-risk students" (p. 232). It appears that students who believe they are able to meet the challenges set before them and can see how the curriculum has real-life application are more motivated to continue with their education and successfully complete graduation requirements.

Anchored Instruction is another method of learning which has been reported to successfully help students retain and use mathematical concepts. Brand (2003) discusses two different studies that focused the effects of project-based instruction, sometimes referred to as anchored instruction. The first study conducted by Boaler in 1998 found that students who learned through open-ended projects had "striking differences in understanding and standardized achievement scores in mathematics" (p. 67) compared to their counterparts. Brand also noted that a second study conducted by The Cognition and Technology Group at Vanderbilt in 1992, "demonstrated that a brief project-based learning experience ('anchored instruction,' in their terminology) can have a significant impact on students' problem-solving skills, metacognitive strategies, and attitudes towards learning" (p. 68). Even though the studies reviewed by Brand were not specific to the alternative setting, it is worth noting that project based lessons are becoming more popular in recent years because they help show students how the curriculum is relevant to their lives. In fact, this method of instruction was identified by Martin, Tobin, and Sugai (2002) as a key strategy used to help prevent alternative education students from dropping out of school. 
Even more specifically, Gagnon and Bottge (2006) studied how a form of anchored instruction was used in a school to overcome instructional challenges such as student turnover, learning disabilities, and behavioral difficulties. The study was conducted at a public charter transition school, and focused on enhanced anchored instruction (EAI) as a way of overcoming these instructional challenges. Gagnon and Bottge describe EAI is a form of anchored instruction which uses multimedia material on CD-ROM and relates it to hands on problems in the classroom. The problems consist of real life projects that have many lower level problems embedded into them. Students at the charter school were given two different EAI problems over 28 days, and then tested on the material. Data analysis showed significant gains in understanding, and students commented that they were learning math without realizing it! The authors concluded that "the use of technology and problem-based learning as delivered in the EAI problems can be effective in boosting the problem-solving skills of youth with LD [learning disabilities], $\mathrm{ED}$ [emotional disturbances], and $\mathrm{BD}$ [behavioral disorders] in alternative settings" (p. 45).

\section{Summary}

As alternative schools across the nation seek to find different means of improving academic skills within their student population, each school has found different ways to meet student needs and state requirements. No one has found a one size fits all approach. So the question remains, what are some of the best approaches Michigan schools can implement in order for students to successfully meet the mathematics HSCEs? 


\section{Chapter 3 - Methodology}

\section{Participants}

All 400 high schools in the state of Michigan identified as active secondary alternative education by the State of Michigan's Department of Education (Michigan Department of Education, 2009) were sent an e-mail invitation asking their mathematics teachers to participate in an online survey related to Best Approaches to Teaching and Aligning Upper Level Mathematics Classes to Michigan High School Content Expectations in an Alternative Education Setting. All participants were made aware of their rights as human subjects participants (MTU protocol M0548; see Appendix B and C for approval letter and informed consent form) and that participation was strictly voluntary. Recruiting participants often relied on administrators to forward the e-mail to the appropriate teachers in their buildings. After a few weeks time, a second e-mail was sent out to schools that had not yet responded inviting them once again to complete the survey and notifying them that the survey portal would close in two weeks.

Sixty unique educators accessed the survey, but only 26 educators completed all of the survey questions and gave permission to use their answers as part of the study. Twenty-three respondents self-identified themselves as classroom mathematics teachers and 3 identified themselves as supervisors who did not directly teach in a classroom. Each participant represented a unique school. For the purposes of this report, only the data from the 26 completed surveys was analyzed. Additionally, 16 educators indicated that they would be willing to participate in a follow-up interview. All of the 16 
participants were contacted for interviews, but only 4 teachers responded and scheduled the interviews.

\section{Data Collection}

The survey (see Appendix A) consisted of 25 informational questions and 2 more questions regarding the participant's willingness to be contacted for an interview and/or to receive a copy of the research results. Questions 1-7 were general characteristic questions, some of which could be used to classify schools by size and type, and teachers by the subjects they taught. Questions 8-16 were Likert-scale type questions with answers ranging from Strongly Disagree to Strongly Agree. These questions were used to gather information about the participants' assessment of HSCE course alignment, quality of implementation, and student success at their school. The remaining questions were open ended and allowed participants to elaborate on their answers. They addressed in greater detail school structure and schedule, the impact of the new HSCEs on classroom mathematics curriculum, specific approaches teachers used to implement the mathematics HSCEs, and also frustrations with implementation that participants experienced. At the end of the survey, participants were given the opportunity to add any other information they thought might be helpful to the study.

Prior to the interview, each of the interviewees was contacted via e-mail and asked to provide a 15-minute block of time and a day when they could be reached by phone. Interviews were designed in a semi-structured format. The participant's responses to the surveys were printed out ahead of time and individual follow up questions were 
constructed so that their personal survey answers could be elaborated upon. For example, many times respondents used language or referred to using technology in their survey answers in ways that needed to be further explained. Questions typically revolved around explaining further their techniques for instruction, the curriculum used in their classrooms, how they defined success for their students, and what areas they felt the state needed to address as The Michigan Department of Education finalizes the HSCEs.

Interview questioning often revealed much more than what was collected in the survey. Since respondents frequently voiced their frustration with the upper level mathematics HSCEs, each interviewee was also asked to describe what they would change about the state's content expectations. For example, if respondents voiced that they believed the requirements for graduation were too stringent, their response was followed up with another question concerning what they believed were appropriate requirements for the students at their school. During each interview, the researcher kept notes that were recorded next to the pre-determined interview questions. Often, respondents would comment on additional information without being prompted and that information was also recorded.

\section{Data Analysis}

Prior to data analysis, each school was assigned a pseudonym ranging from A to Z. The responses from each school's representative were paired accordingly so that the pseudonym was the only identifier associated with their survey and interview responses. 


\section{Open Ended and Interview Responses}

Since participants revealed their school characteristics and level of success in the beginning of the survey, the open-ended responses later in the survey were analyzed first in order to avoid researcher bias. All of the open-ended responses for survey questions 20-25 were coded according to the method of open coding described by Strauss and Corbin (1998). First, survey responses were coded with descriptive labels to capture the main idea of the participants' response using the HyperResearch data analysis software (ResearchWare, 2007). Almost all of the labels fell into two main categories, which were subsequently coded as approaches and issues.

The approaches category described the different ways that schools provided mathematics instruction to students. This category was further subdivided into three major areas: instruction, learning, and technology. A fourth category-other-was also used to identify approaches only mentioned by a single school. Within each coding category more detailed sub-codes were used to identify more descriptively the approaches mentioned by the schools. A summary of the codes is shown in Figure 1.

The issues category identified those areas schools found to hinder the successful implementation of the mathematics HSCEs within the classroom. Issues were separated into 13 distinct codes that are listed in Figure 2. 


\begin{tabular}{|l|l|l|}
\hline $\begin{array}{l}\text { Coding } \\
\text { Category }\end{array}$ & Coding Sub-category & Description \\
\hline Instructional & Individualized & $\begin{array}{l}\text { Instruction specifically tailored to an individual } \\
\text { student }\end{array}$ \\
\cline { 2 - 3 } & Scaffolding & Instruction utilizing a scaffolding technique \\
\cline { 2 - 3 } & Traditional & $\begin{array}{l}\text { Instruction that keeps students at the same pace, } \\
\text { typically utilizing lecture, direct instruction, and } \\
\text { traditional textbook instruction }\end{array}$ \\
\hline Learning & Cooperative & $\begin{array}{l}\text { Students are allowed to learn in a cooperative setting, } \\
\text { working with other students }\end{array}$ \\
\cline { 2 - 3 } & Extended Time & $\begin{array}{l}\text { Students are allowed to complete coursework given } \\
\text { more time (as compared to traditional high school } \\
\text { courses) either during the day or over the life of the } \\
\text { course }\end{array}$ \\
\cline { 2 - 3 } & Hands on & $\begin{array}{l}\text { Students are given opportunities to use hands on } \\
\text { activities in order to facilitate learning }\end{array}$ \\
\cline { 2 - 3 } & Project Based & $\begin{array}{l}\text { Curriculum is often centered around a project as } \\
\text { opposed to a chapter }\end{array}$ \\
\hline Technology & Calculators & $\begin{array}{l}\text { Students have access to and are encouraged to use } \\
\text { graphing calculators }\end{array}$ \\
\cline { 2 - 3 } & Computer Based & $\begin{array}{l}\text { Classes are either solely taught or supplemented using } \\
\text { computer based instruction }\end{array}$ \\
\hline \multirow{2}{*}{ Other } & Any approach that was cited by only one school \\
\hline
\end{tabular}

Figure 1. Coding categories and sub-categories for approaches.

Interview responses were coded using the same approaches and issues coding.

However, since interviews often uncovered a lot more information that fell outside of an approach or issue category that was identified in the survey analysis and only a small number of participants were interviewed, no new code categories were created based upon interview responses alone. And so, some information provided by respondents was left uncoded since it did not fall into a pre-determined category. 


\begin{tabular}{|l|l|}
\hline Code & Description \\
\hline $\begin{array}{l}\text { Algebra 2 not } \\
\text { Universal }\end{array}$ & Algebra 2 content is not appropriate for all students in order to graduate \\
\hline Attendance & Poor attendance \\
\hline Knowledge Gaps & $\begin{array}{l}\text { Students have large gaps in knowledge from previous courses which } \\
\text { prevent them from effectively learning new material }\end{array}$ \\
\hline Lack of Time & $\begin{array}{l}\text { Students do not have enough time left in high school in order to } \\
\text { remediate their mathematics skills and learn all the new required } \\
\text { material }\end{array}$ \\
\hline Low Ability & Students are not capable of learning high level abstract concepts \\
\hline Motivation & Students are not intrinsically motivated to do well \\
\hline Other & Any other issue only mentioned by one school \\
\hline Pace of Course & Too many HSCEs to meet in a normally scheduled class \\
\hline $\begin{array}{l}\text { Real Life } \\
\text { Preparation }\end{array}$ & $\begin{array}{l}\text { Students do not see the value in learning mathematics that does not } \\
\text { directly affect their daily lives }\end{array}$ \\
\hline Retention & Students do not retain information on a day-to-day or weekly basis \\
\hline Transiency & Students frequently move from school to school \\
\hline
\end{tabular}

Figure 2. Codes for issues category.

\section{Classification of Schools}

Schools were sorted according to representatives' response to the statement "Students have mastered $60 \%$ of the HSCEs in my specific course by the time they graduate from school." Those that responded with 'Agree' or 'Strongly Agree' were initially classified as successful in implementing the HSCEs simply because they identified mastery at what is commonly considered the lowest possible passing grade in most high schools. It should be noted that the State of Michigan suggests $70 \%$ as the minimum passing grade on the secondary credit assessments written by the State of Michigan as an option for students to show mastery of the HSCEs, thereby earning credit 
in the course (Michigan Department of Education, 2008). Question 19 was used to further refine the group, with all respondents who did not indicate that the majority (more than $50 \%$ ) of their students completed the course being removed from the successful category. The responses from the remaining successful schools were analyzed for specific teaching strategies that were used to implement the HSCEs.

Although schools G, J, and W all indicated in question 16 (I use a specific teaching strategy or program in order to better facilitate student learning of the HSCEs) that they do not use a specific teaching strategy to implement the HSCEs, within their open-ended responses specific approaches were described. School V, on the other hand, met the criteria for a successful school, but gave no approaches or issues in the survey response and so was removed from the data set. According to school G, only $60 \%$ of the HSCEs were presented in the curriculum yet students mastered $60 \%$ of the HSCEs without an intentional teaching strategy. Since it is very unlikely that all students completing the course had achieved $100 \%$ mastery of the HSCEs presented, school G was classified as neutral instead of successful. Only schools $\mathrm{H}, \mathrm{L}, \mathrm{T}, \mathrm{X}, \mathrm{Y}$, and Z remained in the successful school classification after this analysis.

To identify schools that were unsuccessful in implementing the HSCEs, surveys were first sorted according to participants' response of 'Disagree' or 'Strongly Disagree' to the statement, "Students have mastered $60 \%$ of the HSCEs in my specific course by the time they graduate from school." Only four schools, A, C, K, and O, responded in kind. Their course completion rates were all below $50 \%$ according to question 19 and so the unsuccessful group remained the initial four schools. 


\begin{tabular}{|c|c|c|c|}
\hline Successful & Unsuccessful & Neutral & Removed \\
\hline H & A & B & M (Issues only) \\
J & C & D & Q (Approaches \\
L & K & E & only) \\
T & O & F & V \\
W & & G & \\
X & & I & \\
Y & & M (Approaches & \\
Z & & Only) & \\
& & N & \\
& & P & \\
& & Q (Issues Only) & \\
& & R & \\
& & S & \\
& & U & \\
& & &
\end{tabular}

Figure 3. Category designation for schools.

The remaining schools were categorized as neutral, except for schools Q and V, who each failed to identify any approaches or issues in the open-ended section of the survey. Q and $\mathrm{V}$ were removed from the data set since they had no approaches or issues to contribute. Figure 3 organizes the schools based upon the categories of successful, unsuccessful, neutral, or removed.

After the school classification was complete, approaches and issues within successful, unsuccessful, and neutral schools were compared to each other and compared to the data set as a whole to identify approaches and issues that were common among schools.

\section{Likert-scale Questions}

Other information such as school size, course taught, and type of school district was also taken into account and analyzed for patterns. When responses to the Likert-style questions were analyzed, data for schools $\mathrm{M}$ and $\mathrm{Q}$ remained in the data set since they 
offered at least one approach or issue. However, $\mathrm{V}$ was excluded because they provided no information concerning approaches or issues. In an effort to find other correlations between successful, unsuccessful, and neutral approaches, questions 8-16 responses were coded in the following manner: Strongly Disagree $=0$, Disagree $=1$, Neither Agree or Disagree $=2$, Agree $=3$, and Strongly Agree $=4$. Responses were separated by school category (successful, unsuccessful, neutral) and the mean and standard deviation were calculated for the group overall and for each subgroup. Once it was determined which responses fell outside one standard deviation from the overall mean, approaches and issues were examined carefully to determine if a correlation might exist between how schools taught mathematics and viewed problems with implementing the HSCEs and their categorization as successful, unsuccessful, or neutral. 


\section{Chapter 4 - Results}

Once all of the schools were categorized as successful, neutral, or unsuccessful, each school's approaches and issues were compiled into the two tables below. Figure 4 summarizes the approaches taken by the individual schools and Figure 5 summarizes the issues cited.

Each school's responses were marked with a single letter or comment in the chart to indicate whether a particular approach or issue was associated with a successful (S), unsuccessful (U) or neutral (N) school. Although the same approaches and issues were often cited multiple times within a school's response, when the charts were compiled, duplicity was not taken into account. For instance, if a school cited 'Individualized Instruction' repeatedly throughout the open-ended responses, it simply appears as an S, $\mathrm{U}$, or $\mathrm{N}$ in the figure below, indicating that the school mentioned it as an approach being used in the classroom. Rows were also shaded to visually aid in discerning between categories. All successful schools were shaded in light gray with black text, unsuccessful schools were shaded in black with white text, and neutral schools were left unshaded.

In the following, I first discuss patterns between how a school was categorized and the school's characteristics such as size, type, content taught, etc. Then, I analyze differences in approaches and issues between school categories (successful, unsuccessful, and neutral) to see if there were any striking similarities or differences. Finally, I discuss the Likert-type question responses, and calculated means and standard deviations to identify differences between how schools in different classifications responded. 

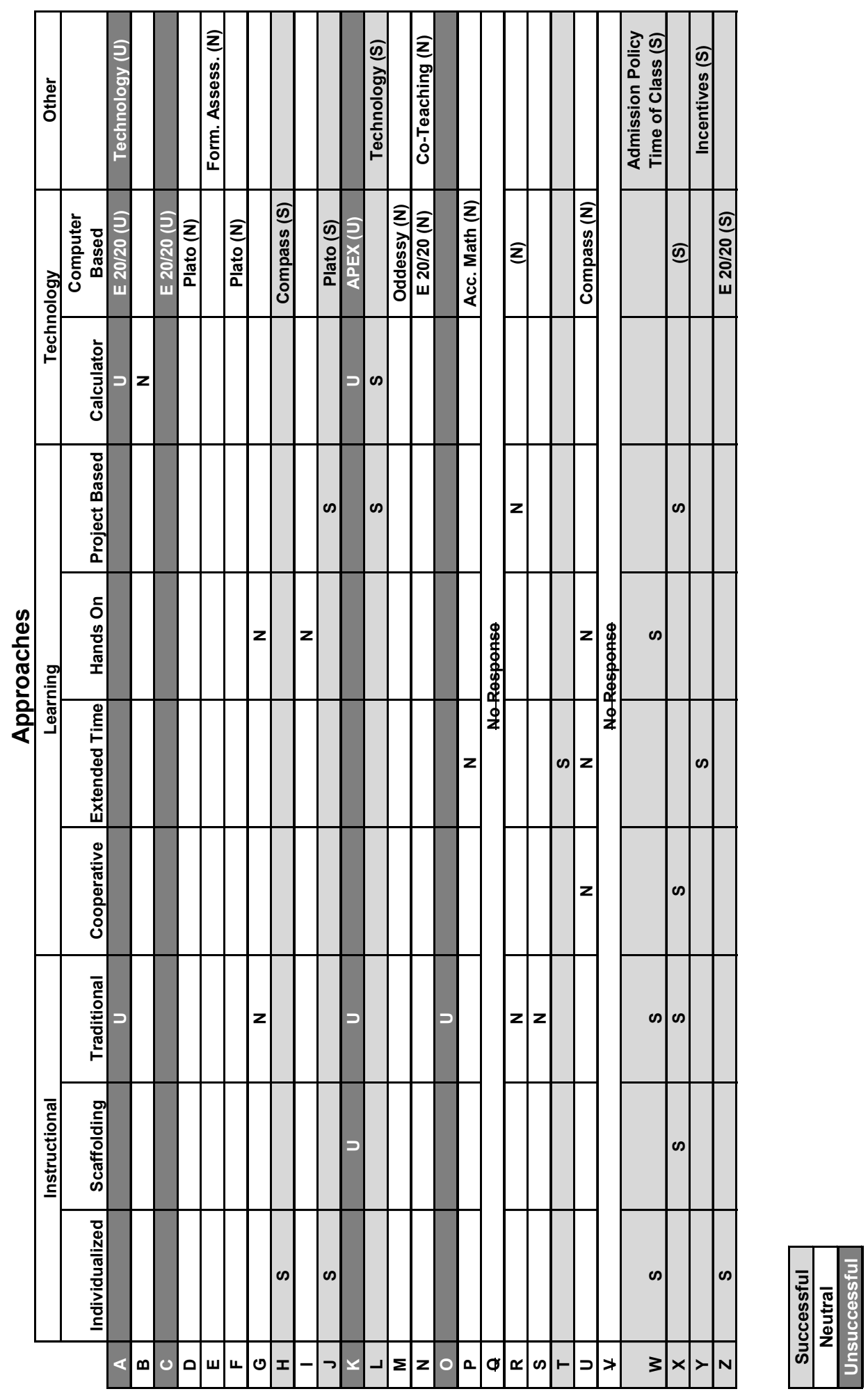

Figure 4. Approaches table summarized by school category. 

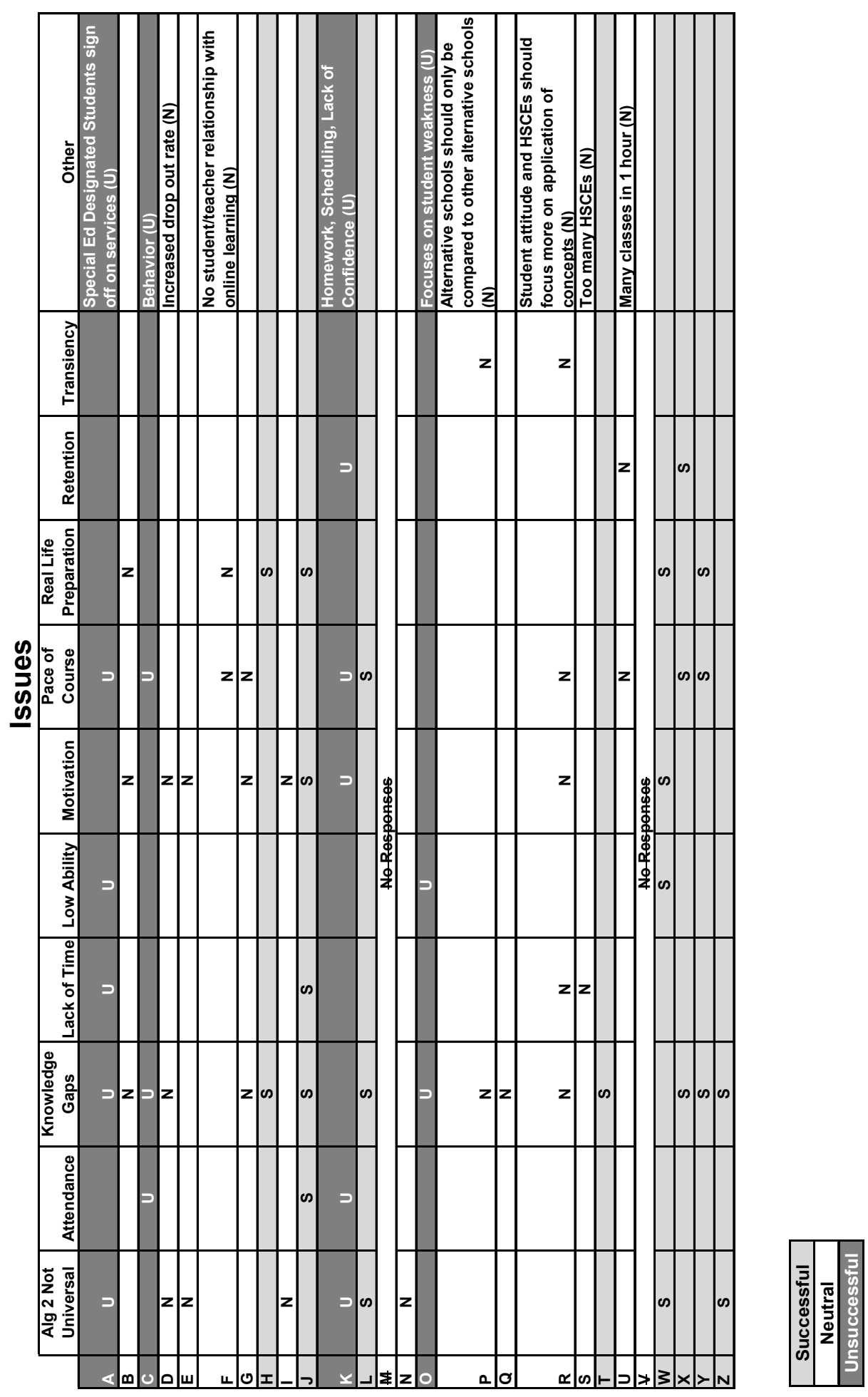

Figure 5. Approaches table summarized by school category. 


\section{School Characteristics}

Of the eight schools labeled as 'successful', three were described as rural, four as suburban, and one as urban. As could be expected, their school enrollment ranged similarly from 20 in the more rural districts to over 1300 in the urban district. Split evenly down the middle, four schools answered the survey based upon an Algebra 2 course and the other four schools based upon a Geometry course. Class sizes ranged anywhere from 5 students at the low end to no more than 25 students at the high end.

Two rural and two suburban schools were identified as 'unsuccessful'. Of these, three respondents referred to Algebra 2 courses and one respondent referred to a Geometry course. Class sizes ranged from 13-22 and school enrollments ranged from 50200.

Thirteen schools were categorized as 'neutral'. Six of them were rural and seven were suburban. The most diversity in classes taught was found in this category. Five schools referred to Algebra 2 courses, two schools referred to an Algebra 1 course, four referred to Geometry, one referred to Pre-calculus, and one gave no course description at all. Total school enrollment also was very broad, ranging from 25 to 250 students. Class size descriptions ranged from 3 to 25 with a couple of respondents referring to students taking an online curriculum and not divulging how many students were in a classroom at one time.

Thus, there was a good amount of diversity in every school classification category. No particular correlations could be seen between school type, school 
enrollment, class size, or the type of class offered and the level success a school a school reported having in implementing the HSCEs.

\section{Approaches}

Figure 4 summarizes the different approaches taken by schools in implementing the HSCEs. For the most part successful, unsuccessful, and neutral schools all relied on some traditional teaching methods and calculator use. Fourteen out of $24(58 \%)$ of the schools also reported infusing computer-based technology into their classrooms either as the sole means of instruction or as a supplement to instruction. Slightly less, $50 \%$, of the successful schools cited it as an approach utilized in their classrooms. However, none of the successful schools cited the same program or the same technique of implementation. Because of this, it does not appear that traditional teaching methods, calculator use, or computer based technology have a great impact on how successful a school is in implementing the HSCEs.

Conversely, individualized instruction was only cited as an approach used by successful schools. For example, School J wrote, "All math classes are individualized. Students may work from the book, off worksheets, [or] on Plato (a computer based program)," indicating that students used a variety of learning methods to meet their individual needs. There were no recorded instances of unsuccessful or neutral schools using individualized instruction in the classroom. Although only $50 \%$ of the successful schools claimed to tailor instruction to individual students, it is quite significant that no 
other type of school made this claim, and it is possible that individualized instruction might be more likely to lead to successful implementation of the HSCEs.

It is also quite alarming that none of the learning approaches (cooperative, extended time, hands on, and project based) were cited by a school that was classified as unsuccessful. Of the 14 instances that respondents referred to a specific learning approach, 7 were cited by a representative of a successful school and 7 were cited by a neutral school representative.

Even more specifically, project based instruction was marked as a successful approach in 3 of the 4 instances that it was cited and was cited by $38 \%$ of the successful schools. This data is in agreement with the research of Brand (2003), which claims that project-based learning can have a significant positive impact on student learning.

Even though some instructional approaches were only mentioned by a single school, it is worth noting that two of the successful schools cited using unique approaches. School Y reported that incentives are used to promote student learning, specifically, "students earn privileges by maintaining a C- or better in all their classes." Similar to the approach reported by Tufly (2001), School W had strict admission policies, but without testing requirements. School W's representative was very supportive of a new change they recently made after learning of research presented at a national education conference. This research prompted their school to change the time of day in which mathematics classes were offered to mid-morning, and their school has found it to be extremely successful in increasing student learning. 


\section{Issues}

Since the inception of Michigan's HSCEs, educators have been voicing their concerns about these requirements. One of the purposes of this survey was to identify the most common issues alternative school educators face as they implement the new standards in their classrooms. While approximately 23 different issues were mentioned by the 24 responding schools, only 11 of the issues were identified by more than one school. Table 1 below lists these common issues according to the proportion of schools that cited them. All of the specific issues, even those cited only once, can be found in Figure 5.

Table 1. Issue Frequency.

\begin{tabular}{lcccc}
\hline \multicolumn{1}{c}{ Code } & All schools & $\begin{array}{c}\text { Successful } \\
\text { schools }\end{array}$ & $\begin{array}{c}\text { Unsuccessful } \\
\text { schools }\end{array}$ & $\begin{array}{c}\text { Neutral } \\
\text { schools }\end{array}$ \\
\hline Knowledge Gaps & $67 \%$ & $88 \%$ & $75 \%$ & $50 \%$ \\
Pace of Course & $42 \%$ & $38 \%$ & $75 \%$ & $33 \%$ \\
Algebra 2 not Universal & $38 \%$ & $38 \%$ & $50 \%$ & $33 \%$ \\
Motivation & $38 \%$ & $25 \%$ & $25 \%$ & $50 \%$ \\
Real Life Preparation & $25 \%$ & $50 \%$ & $0 \%$ & $17 \%$ \\
Lack of Time & $17 \%$ & $13 \%$ & $25 \%$ & $17 \%$ \\
Low Ability & $13 \%$ & $13 \%$ & $50 \%$ & $0 \%$ \\
Attendance & $13 \%$ & $13 \%$ & $50 \%$ & $0 \%$ \\
Retention & $13 \%$ & $13 \%$ & $25 \%$ & $8 \%$ \\
\hline
\end{tabular}

By far, addressing gaps in student knowledge was the most commonly cited issue over all. Eighty-eight percent of the successful schools mentioned it as the number one hurdle they face in the classroom. School J, for example, commented that, "Students have had social promotion for many grades and do not have the necessary skills to do math. They do not know multiplication tables and cannot use fractions. If a student has a D- in 
Pre-Algebra or Algebra then they have credit, but not competency." Schools classified in the other categories concurred, since at no time was this issue mentioned by less than $50 \%$ of the schools in any category.

The second most frequently cited issue, mentioned by $42 \%$ of the schools, was helping students keep up with the pace of the course. Successful schools ranked this as the third issue, but the representative from School X may have said it best in the response, "Like everyone else, it seems we can either teach several HSCEs well, or all HSCEs poorly." It seems that this was the general consensus among schools. It may come as no surprise that alternative schools have trouble keeping up with the pace, especially if they are focused on addressing knowledge gaps before presenting the content of the course.

'Low Ability' and 'Low Attendance' were each cited by 3 separate schools. Two of the schools listing them as an issue were categorized as unsuccessful and the other school mentioning them was a successful school. This may suggest that unsuccessful schools often have more problems with attendance and have a greater proportion of lower level students than successful schools experience. However, because the data set is small, it is difficult to discern if this correlation would apply more broadly to alternative schools throughout the state.

Although the appropriateness of requiring Algebra 2 for all students who wish to earn a diploma may not necessarily hinder the implementation of the HSCEs in the classroom, it definitely draws attention to the feelings of educators throughout the state. 
School W echoed the thoughts of many of the other schools in the response, "It does not allow for individualization. Many of our students would be better served taking a consumer math [course] rather than Algebra 2." In fact it should be noted that when the issues of 'Algebra 2 not being appropriate' and 'The lack of real life preparation' are combined, 14 out of the 24 schools made mention of one or the other. Six out of the eight successful schools agreed, with four of them citing the lack of real life preparation as a huge hindrance to implementing the HSCEs in their classroom. School H summarized the thoughts of others well in the response, "I wish that the state would take into consideration that not every student is going to [go] off to college and earn a degree. They need to have practical real life math. Most of our students are going to stay here in town and get regular everyday jobs, that's what they need to learn." With less than half of respondents supporting the Algebra 2 requirement for graduation and its inclusion in the HSCEs, this issue, though not directly affecting the implementation of the Algebra 2 HSCEs in classroom, may be indirectly impacting the students. If educators are not sold on the idea of Algebra 2 for all students, then how can students be expected to be on board?

\section{Other Possible Contributing Factors}

Questions 8-16 were Likert-scale type questions that required representatives to answer with a response ranging from Strongly Disagree to Strongly Agree. During analysis, these were assigned numerical values as follows: Strongly Disagree $=0$, Disagree $=1$, Neither Agree or Disagree $=2$, Agree $=3$, and Strongly Agree $=4$. Responses were separated by school category and the mean was calculated for the group 
overall and for each school category. The means and standard deviations for each question — for the whole group and each school sub-group — are recorded in Table 2 below.

Table 2. Average Responses to Questions 8-16 and Question 18 by School Category.

\begin{tabular}{|c|c|c|c|c|c|c|c|c|}
\hline \multirow[t]{3}{*}{ Questions } & \multicolumn{2}{|c|}{ Overall } & \multicolumn{2}{|c|}{ Successful } & \multicolumn{2}{|c|}{ Unsuccessful } & \multicolumn{2}{|c|}{ Neutral } \\
\hline & Mean & SD & Mean & SD & Mean & SD & Mean & SD \\
\hline & \multicolumn{2}{|c|}{$\mathrm{n}=25$} & \multicolumn{2}{|c|}{$\mathrm{n}=8$} & \multicolumn{2}{|c|}{$n=4$} & \multicolumn{2}{|c|}{$\mathrm{n}=13$} \\
\hline $\begin{array}{l}\text { 8.) I have a working knowledge of the } \\
\text { Michigan High School Content } \\
\text { Expectations (HSCEs) for my specific } \\
\text { course. }\end{array}$ & 3.29 & 1.00 & 3.13 & 1.46 & 2.75 & 0.96 & 3.58 & 0.51 \\
\hline $\begin{array}{l}\text { 9.) My specific course's curriculum } \\
\text { covers } 80 \% \text { or more of the HSCEs set } \\
\text { forth by the state. }\end{array}$ & 3.08 & 1.02 & 3.38 & 0.52 & 2.00 & 1.83 & 3.25 & 0.75 \\
\hline $\begin{array}{l}\text { 10.) Students have mastered } 60 \% \text { or } \\
\text { more of the HSCEs in my specific } \\
\text { course by the time they graduate from } \\
\text { school. }\end{array}$ & 2.42 & 0.97 & 3.00 & 0.00 & 0.75 & 0.50 & 2.58 & 0.79 \\
\hline $\begin{array}{l}\text { 11.) I specifically write my assessments } \\
\text { in my specific course to cover the } \\
\text { HSCEs. }\end{array}$ & 2.79 & 0.98 & 2.63 & 1.19 & 2.75 & 0.96 & 2.92 & 0.90 \\
\hline $\begin{array}{l}\text { 12.) Michigan's HSCEs determine what I } \\
\text { teach in my specific course. }\end{array}$ & 3.17 & 0.92 & 3.00 & 1.07 & 3.25 & 0.96 & 3.25 & 0.87 \\
\hline $\begin{array}{l}\text { 13.) Teaching to Michigan's HSCEs in } \\
\text { my specific course helps my students } \\
\text { learn what they need to know to be } \\
\text { successful after high school. }\end{array}$ & 2.00 & 1.22 & 1.75 & 1.58 & 2.00 & 1.15 & 2.17 & 1.03 \\
\hline $\begin{array}{l}\text { 14.) I have made adjustments to the } \\
\text { manner in which I teach in order to align } \\
\text { my specific course with the HSCEs. }\end{array}$ & 2.79 & 0.98 & 2.88 & 0.83 & 3.50 & 0.58 & 2.50 & 1.09 \\
\hline $\begin{array}{l}\text { 15.) I feel that my approach to meeting } \\
\text { the HSCEs has been successful. }\end{array}$ & 2.42 & 0.83 & 2.38 & 0.74 & 2.00 & 0.82 & 2.58 & 0.90 \\
\hline $\begin{array}{l}\text { 16.) I use a specific teaching strategy or } \\
\text { program in order to better facilitate } \\
\text { student learning of the HSCEs. }\end{array}$ & 2.17 & 1.17 & 2.50 & 0.93 & 1.75 & 1.71 & 2.08 & 1.16 \\
\hline $\begin{array}{l}\text { 18.) Approximately what percent of the } \\
\text { HSCEs for your specific course do you } \\
\text { address in class? }\end{array}$ & $76 \%$ & $17 \%$ & $83 \%$ & $10 \%$ & $53 \%$ & $15 \%$ & $79 \%$ & $14 \%$ \\
\hline
\end{tabular}


It is not coincidental that question 10 shows a stark contrast between successful and unsuccessful schools, because this question was initially used to categorize schools. However, each of the remaining questions reveal some important information.

The question 8 responses indicate that all schools averaged a positive response for having a working knowledge of the HSCEs. It appears that though the unsuccessful schools registered slightly lower than the successful schools in their rating, their respective means still fall within one standard deviation of the overall mean, suggesting that having a working knowledge of the HSCEs does not directly impact how successful a school is at implementing them.

Question 9 responses seem to indicate a direct correlation between the percent of HSCEs taught in the curriculum and the successful implementation of them in the classroom. The overall responses to this question actually contradicted the claim of $17 \%$ of the respondents who voiced that there simply wasn't enough time to present enough of the HSCEs in the classroom. It could be that successful schools feel the same time pinch as neutral and unsuccessful schools, but instead of succumbing to it, still manage to integrate $80 \%$ or more of the HSCEs. In contrast, unsuccessful or neutral schools only teach as many HSCEs as they are able to manage in the course's time frame. The data shows that the unsuccessful schools' average response of 2.00 actually falls outside of one standard deviation of the overall mean, and thus, this factor may indicate that the difference in the amount of HSCEs implemented between successful and unsuccessful schools could be important. Presenting less than $80 \%$ of the HSCEs in the classroom 
would naturally make it more difficult for students to meet the recommended $60 \% \mathrm{HSCE}$ master requirement.

Ironically, successful schools consistently scored lower than neutral or unsuccessful schools in their responses to whether they intentionally aligned their curriculum to the HSCEs, both concerning assessments and what is being presented in the classroom. This could be an indication that teaching to a test or teaching specifically to a set of standards like the HSCEs, actually impairs a teacher's ability to present material in a successful fashion. Question 14 may support this theory since unsuccessful schools claimed to have made significantly more adjustments in the way that they teach in order to better implement the HSCEs, whereas successful schools and neutral schools scored positively, but not quite to the degree of agreeing with the statement.

Similarly, the measure of alignment between curriculum and HSCEs, as reported in question 18 , shows that overall schools reported a $76 \%$ alignment between the curriculum taught in their classrooms and the HSCEs set forth in the Michigan Merit Curriculum. Successful and neutral schools reported a slightly higher average of $83 \%$ and $79 \%$, but unsuccessful schools reported an overall average of 53\%. Again, this low score places the unsuccessful school average well outside of one standard deviation from the overall mean. However, successful and unsuccessful schools were originally sorted at the $60 \%$ level of HSCE implementation, so the difference in means between school categories to some extent was already built-in. 
The only time successful schools ever averaged an overall negative score was to question 13 (Teaching to Michigan's HSCEs in my specific course helps my students learn what they need to know to be successful after high school.). This may suggest that although the schools seem to be successful at implementing the HSCEs, respondents are not necessarily convinced that the HSCEs are teaching their students what they need to know to be successful. This could be troublesome if the most successful schools are not convinced that the HSCEs are preparing their students for real life. Furthermore, it does not bode well for the longevity of the HSCEs as written if teachers are asked to continue to follow a set of standards that they do not feel are in the best interest of their students.

While neutral schools believe they have had the most success with their instructional approaches, strangely, they only averaged a 2.58 for question 15 . This actually falls 0.42 points below a 3, which represents an 'Agree' rating. It is a bit troubling that no category of school, individually or overall, actually met or exceeded an 'Agree' level to the question, 'I feel that my approach to meeting the HSCEs has been successful. 


\section{Chapter 5 - Discussion and Conclusion}

\section{Discussion}

\section{Approaches}

The data presented in the approaches category seems to suggest that schools that intentionally provide individualized instruction to students have more success in implementing the mathematics HSCEs in their classrooms than those schools that do not

provide such instruction. However, of the four successful schools that cited this particular approach, no one class averaged more than twelve students. Thus, smaller classes may have been a contributing factor that enabled these schools to individualize instruction. However, an approach such as this that seems to have a lot of positive effects on student learning may be able to be implemented on a larger scale given the proper supports.

Conversely, it might be gathered that altering an instructional approach doesn't solely guarantee successful results, as it appears that successful schools also focus on different ways to facilitate student learning. Seventy-five percent of the successful schools also incorporated new approaches to learning, such as cooperative learning, giving extended time, using hands-on activities, or project based assignments, whereas unsuccessful schools never identified a specific learning approach when implementing the HSCEs. A combination of individualized instruction and intentional learning approaches best characterized successful schools, and a lack of individual instruction and learning approaches often characterized unsuccessful schools. 
While there is a big push for incorporating computer-based learning in alternative school settings, little evidence was found that it actually improved students' ability to learn the HSCEs. In fact, one school actually had a negative opinion of computer-based learning because the respondent believed that the student-teacher relationship was often missing. If this is true, computer-based instruction may actually work against the very idea that individualized instruction promotes. While the majority (14 out of 24) of responding schools actually reported using some form of computer-based instruction in their classrooms, no correlation between school success and this approach could be determined.

\section{Issues}

Gaps in student knowledge consistently emerged as the greatest concern to schools. Alternative education teachers frequently get students who are behind in classes and credits, so holding them to the same amount and level of work as a regular education student, with a shorter amount of time to complete it, automatically poses a problem for the teacher and the student alike. Teacher frustration with knowledge gaps in student learning was identified as the leading obstacle in implementing the HSCEs successfully.

Teaching to a test or a set of standards has also been an issue among educators for years. The data showed that all schools feel the need to look at and consider the HSCEs as they determine what is best to teach their students and that addressing at least $80 \%$ of the HSCEs in the curriculum is beneficial. However, those schools that intentionally set out to write tests and present curriculum aligned with the HSCEs found the least amount 
of success. Successful teachers seemed to have the mindset that using the HSCEs as a guide rather than as a checklist of things to be taught and focusing on individual instruction and other learning methods best served the students. Perhaps when an educator's attention is focused more on how something is taught rather than the specifics of what is taught, students benefit.

Whether or not Algebra 2 is an appropriate class for everyone was a resounding theme throughout the surveys and interviews. Mathematics instructors in the alternative setting are having a hard time justifying teaching upper level abstract mathematics topics to students who struggle to make it through Algebra 1 and who see no relevance of these topics to their future careers or their daily lives. The debate about making Algebra 2 a mandatory class for graduation is still going on in the Michigan Legislature today and new mandates and adjustments seem to be rolling out on a monthly basis. However, in the meantime, justifying this particular class to teachers, parents, and students has become an issue of great debate, and one that alternative school teachers, especially alternative teachers in schools categorized as successful (75\%), still have not supported.

\section{Limitations}

Even though 400 schools were contacted, only $6.5 \%$ of them responded. And so, because of the smaller data set, the question about how far the research results can be applied to other districts remains. This study also relied solely upon an individual's assessment of his or her own programs. No other outside means of measurement was used to determine a school's ability to implement the HSCEs in upper level mathematics. 
Because of this, the results are only as accurate and reliable as the individuals who reported them.

Also, there were times when respondents left questions blank. Non-answers could not be used in the data and some schools that were initially categorized as successful were removed from the category because of a lack of responses. Another limitation of the study was the lack of documentation concerning admission policies. Since this issue was not specifically addressed, and it only arose if a respondent mentioned it in an openended response, schools that were able to choose their students and those who had to take anyone were not segregated. It may have been helpful to discern between schools who were able to pick their clientele and those who were not.

Additionally, interviews often had questions to the researcher from the respondents which may have introduced more researcher bias. For instance, interviewees would ask questions to the researcher such as, "Do you find you have the same struggles in your classroom?" or "How do your students respond to the new Algebra 2 requirement?", because of the back-and-forth communication sometimes involved in a semi-structured interview format. Thus, the researcher's own classroom experiences could have biased the interviewee's responses.

\section{Areas for Further Research}

It would be very interesting to consider how the categories of success in this study align with standardized test results from the schools. Since the State of Michigan uses the Michigan Merit Exams (MME) as a measure of success (Michigan Department of 
Education, 2009) the results of this test would provide further insight as to how accurate a school's representative reported their success, and in turn, would provide greater insight as to what approaches are successful and unsuccessful when implementing the mathematics HSCEs.

Furthermore, if implementing more individualized instruction makes a significant impact on student success, it would be helpful to know more about the specific ways that teachers individualize instruction. Are they working in a one-on-one fashion? Do they teach different content to different students within the same mathematics class? Or are they using computer-based instruction as their sole means of individualization? Once the method of individualization is specified, it would also be helpful to consider how schools with larger size classes go about implementing individualized instruction.

Finally, according to this study, knowledge gaps were identified to be by far the greatest hurdle to overcome when implementing the HSCEs. However, very little information was obtained as to how schools are addressing this problem. It may be helpful to further investigate how successful schools address the issue.

\section{Conclusion}

Teachers in alternative education settings face the daunting task of catching up many students who have fallen behind in the regular education system. Students enter alternative education for many reasons, but according to the State of Michigan, they are required to meet the same requirements for graduation as a student in a regular high school setting. The results of this study suggest that the best way to implement the 
HSCEs in an upper level mathematics class is through individualized instruction, a variety of different learning techniques, and by showing students how the curriculum is relevant to their everyday lives.

According to school representatives, the number one issue with implementing the HSCEs is overcoming students' knowledge gaps. The best ways to address this issue cannot be determined in this study, but educators are feeling increasingly pressured to teach more and more in a shorter amount of time. Frequently, alternative educators voiced their disagreement with the mandatory Algebra 2 requirement for their students. Many expressed that their schools population would be better served by substituting a consumer-mathematics-type course in its place. However, as of the date of this study, no changes have yet to be made. This coming school year, the students in the class of 2011 will be required to complete a year of Geometry, and at least a full semester of Algebra 2 in order to earn a diploma. It remains to be seen how successfully alternative education across the State of Michigan will be in fulfilling this requirement and how these new requirements will impact graduation rates within the schools. 


\section{Appendix A - Survey}

Teaching and Aligning Upper Level Mathematics Classes to Michigan HSCEs in an Alternative Education Setting: Approaches and Issues

Please provide the following information:

1) Informed Consent: Please Read the Informed Consent Below. If you agree to it, please indicate below. If you do not agree, the survey will discontinue.

\section{(Insert Informed Consent Page Here)}

2) School Name (will be removed from all research data and is only for the purpose of determining which schools have responded)

3) Rural, Urban, or Suburban District

4) Your occupation title

5) Approximate student enrollment in your alternative school

6) Please choose one upper level math class you teach and enter the name below. Please refer to this specific course when responding to all further questions.

7) Approximate class size for your specific course.

All of the questions to follow will be in direct reference to the class you choose in question 6 above.

For the following questions 8-16, please choose one of the following:

Strongly Disagree Disagree Neither Agree or Disagree Agree Strongly Agree

8) I have a working knowledge of the Michigan High School Content Expectations (HSCEs) for my specific course.

9) My specific course curriculum covers $80 \%$ or more of the HSCEs set forth by the state. 
10) Students have mastered $60 \%$ of the HSCEs in my specific course by the time they graduate from school.

11) I specifically write my assessments in my specific course to cover the HSCEs.

12) Michigan's HSCEs determine what I teach in my specific course.

13) Teaching to Michigan's HSCEs in my specific course helps my students learn what they need to know to be successful after high school.

14) I have made adjustments to the manner in which I teach in order to align my specific course with the HSCEs.

15) I feel that my approach to meeting the HSCEs has been successful.

16) I use a specific teaching strategy or program in order to better facilitate student learning of the HSCEs.

Open-Ended Questions

17) What type of daily schedule does your school implement? Approximately how long is each class? Does your school use semesters, trimesters, or some other format?

18) Approximately what percent of the HSCEs for your specific course do you address in class?

19) What percent of students currently complete your specific course? How does this compare to the percent completion before the HSCEs were implemented?

20) What are some of the main challenges you face in meeting the HSCEs in your specific course's curriculum?

21) What other upper level math courses do you teach or are offered in your school?

22) What approaches have you found helpful in meeting the HSCEs for mathematics in your courses or in your school? (For instance do you follow a certain type of instruction such as 'anchored instruction', incorporate the use of technology, or have project based assignments for all subjects?) Please be as detailed as possible in your description here. 
23) What issues, if any, are you or your school struggling with as you work to meet the HSCEs in upper level math?

24) Are there any areas you wish to see the state address as it revises and finalizes the HSCEs for upper level math?

25) Is there any other information you think might be useful for the purposes of this study?

26) Are you willing to be contacted by the researcher to participate in a 10-20 minute follow-up phone interview? If so, please provide your name, email address and phone number (your name will not be included with any of your responses in the study data).

27) Would you like to be notified as to how to review the results of this study when it is complete? If so, please provide your e-mail address below. 


\section{Appendix B - Approval Letter}

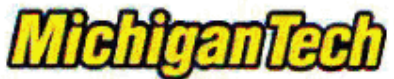

Michigan Technological University

\section{Office of Research Integrity and Compliance}

302 Lakeshore Center

MEMO

TO: Dr. Shari Stockero, CLS

CC: Sarah Van Baale, CLS

FROM: Joanne Polzien, Director Research Integrity and Compliance

DATE: January 28, 2010

\section{SUBJECT: Approval M0548}

Your application to use human subjects in research or classroom situations has been reviewed with the following determination:

\section{Protocol \#: M0548}

Protocol Title: "Best Approaches to Teaching and Aligning Upper Level Math Courses to Michigan HSCEs in an Alternative Education Setting "

Approved Dates: January 28, 2010 through January 27, 2011

Approvals are granted for up to a one year period. You will need to request a continuation for cach ycar of the project six weeks prior to the end date indicated above for each year of the project. The Office of Research Integrity and Compliance will make every effort to send the Principal Investigator annual reminders. However, the Principal Investigator is responsible for submitting annual Continuation Forms in advance of the expiration date for the project. It is very important that these expiration dates are not missed. Failure to submit annual review materials on time will result in the termination of this protocol.

This approval applies only for this project, and only under the conditions and procedures described in the application; if any changes are made in the protocol or conditions set forth in the application, the principal investigator must obtain a separate approval before these changes take place. The approved project will be subject to surveillance procedures requiring periodic review. This review will consist of consulting with the principal investigator and examining the appropriate project records.

Individual identification of human subjects in any publication is an invasion of privacy. Before beginning a project involving human subjects, and only if required, the principal investigator must obtain a properly executed informed consent from each subject and/or the person legally responsible for the subject. If a consent form has been reviewed and approved it has been attached with an official date stamp on it. Only copies of the official date stamped informed consent is to be distributed to participants relating to this project. If any changes or modifications are needed regarding this form, you must first submit the revised document for review and approval prior to use. The principal investigator must retain informed consent forms on file for at least three years after the end of the project. If a project involves a high level of risk, copies of the signed informed consent forms must be filed with the Human Subjects Committee; if this is the case, you will be notified.

This document is on file in the Office of Research Integrity and Compliance, If you bave any questions, please contact me at 487-2902 or jpolzien@mtu.edu. 


\section{Appendix C - Informed Consent}

\section{CONSENT TO PARTICIPATE IN RESEARCH Best Approaches to Teaching and Aligning Upper Level Math Classes to Michigan HSCEs in an Alternative Education Setting}

[to be included at beginning of online survey]

You are invited to participate in a research study conducted by Dr. Shari Stockero and Sarah Van Baale (Master of Applied Science Education Candidate) from the Department of Cognitive and Learning Sciences at Michigan Technological University. Your participation in this study is entirely voluntary. Please read the information below and email either researcher (stockero@mtu.edu orsvanbaale@gmail.com) with questions about anything you do not understand before deciding whether or not to participate.

\section{Purpose of this Study}

The study has four distinct goals. The first goal is to discover how alternative high schools across Michigan are changing their math program to better address the High School Content Expectations. We would like to note the extent to which each school's math curriculum is aligned with the HSCEs, and also how effective school personnel feel their changes have been. Finally, we would also like to summarize issues that schools have not yet resolved. Since graduation requirements have recently been changed to include Geometry, Advanced Algebra, and/or another senior level math subject, many alternative education programs have had to offer new classes and change previous classes. The study aims to develop a better understanding of how changes at the state level are affecting alternative education programs.

\section{Procedures}

You are being invited to be a participant in this study about meeting the HSCEs in an alternative education setting. If you agree to participate in this study, you will be asked to do the following things:

1) You will be asked to fill out an online survey based upon your knowledge as a teacher of an upper level math course in an alternative education setting.

2) You may be invited to participate in a short follow up phone interview after all the survey data has been collected and organized. The purpose of the interview will be to gather additional information related to your survey responses.

3) Give permission to use your survey responses and possibly interview responses as part of the data for this study. Your name and your school name will be removed from all work to insure confidentiality.

\section{Potential Risks and Discomforts}

The only potential known risk would be the loss of time in filling out the survey and possibly participating in a phone interview. It is believed that the potential benefits of engaging in this process outweigh any risks. 
In the event of physical and/or mental injury resulting from participation in this research project, Michigan Technological University does not provide any medical, hospitalization or other insurance for participants in this research study, nor will Michigan Technological University provide any medical treatment or compensation for any injury sustained as a result of participation in this research study, except as required by law.

\section{Potential Benefits to Subjects and/or to Society}

This work will benefit alternative schools and teachers across the state as the study will highlight best practices and common concerns related to aligning and implementing a curriculum for upper level math courses in an alternative education setting in accordance with the Michigan High School Content Expectations. Participation in the study may benefit you directly through the opportunity it provides you to reflect on your curriculum.

\section{Confidentiality}

Any information that is obtained in connection with this study and that can be identified with you or your school will remain confidential and will be disclosed only with your permission or as required by law. Confidentiality will be maintained by removing participant names from all data. Only the researcher will have access to the raw data; it will be stored in a secure location. Each participant and/or school will be assigned a pseudonym that will be used in all written reports resulting from this work.

\section{Participation and Withdrawal}

You can choose whether or not to be in this study. If you volunteer to be in this study, you may withdraw at any time without consequences of any kind or loss of benefits to which you are otherwise entitled. You may also refuse to answer any questions you do not want to answer.

\section{Identification of Investigators}

If you have any questions or concerns about this research, please contact Dr. Shari Stockero at (906) 487-1126 or stockero@mtu.edu or Sarah Van Baale at svanbaale@gmail.com

\section{Rights of Research Subjects}

The Michigan Tech Institutional Review Board has reviewed my request to conduct this project. If you have any concerns about your rights in this study, please contact Joanne Polzien of the Michigan Tech-IRB at 906-487-2902 or email jpolzien@mtu.edu.

[Participants will choose one of the following in the online survey. The survey will be ended if they choose the second option.]

I understand the procedures described above. My questions have been answered to my satisfaction, and I agree to participate in this study.

I do not wish to participate in this study (please close your browser to discontinue the survey). 


\section{References}

Alfassi, M. (2003). Promoting the will and skill of students at academic risk: An evaluation of an instructional design geared to foster achievement, self-efficacy and motivation. Journal of Instructional Psychology, 30(1), 28-40.

Brand, B. (2003). Essentials of high school reform: New forms of assessment and contextual teaching and learning. Washington, DC: American Youth Policy Forum.

Dicintio, M. (1999). Control is the key: Unlocking the motivation of at-risk students. Psychology in the Schools, 36(3), 231-237.

Finnan, C. \& Chasin, G. (2007). Accelerating the learning of low-achieving students: The transformation of a dropout. Phi Delta Kappan, 88, 625-629

Gagnon, J. \& Bottge, B. A. (2006). Mathematics instruction in secondary interim, shortand long-term alternative school placements. Preventing School Failure, 51, 3947.

Grunbaum, J., Kann, L., Kinchen, S., Ross, J., Gowda, V., Collins, J., \& Kolbe, L. (2000). Youth risk behavior surveillance national alternative high school youth risk behavior survey, United States 1998. Journal of School Health, 70(1), 5-17.

Guerin, G., \& Denti, L. (1999). Alternative education support for youth at-risk. The Clearing House, 73 (2), 76-8

Katsiyannis, A., \& Williams, B. (1998). A national survey of state initiatives on alternative education. Remedial and Special Education, 19(5), 276-284. 
Lange, C. M. (1998). Characteristics of alternative schools and programs serving at-risk students. The High School Journal, 81, 183-198.

Martin, E., Tobin, T., \& Sugai, G. (2002). Current information on dropout prevention: Ideas from practitioners and the literature. Preventing School Failure, 47(1), 1017.

Michigan Department of Education (2006). Michigan high school content expectations. Retrieved from http://www.michigan.gov/documents/mde/111706finalhsfaq_178578_7.pdf.

Michigan Department of Education (2008). Michigan secondary credit assessments for Algebra I, Geometry, Biology and English 9. Retrieved from http://www.michigan.gov/documents/mde/OEAA_Memo_to_Supts_re_ Secondary_Credit_Assessments_5-13-08_242231_7.pdf

Michigan Department of Education (2009). EEM search schools and UEPs with alternative ed. Retrieved from http://www.michigan.gov/documents/mde/Alt_Ed_Search_Directions_ 190917_7.pdf

Michigan Department of Education (2009). MME Michigan merit exam. Retrieved from http://www.michigan.gov/mde

Michigan Department of Education (2010). Personal curriculum: Parent and educator guide. Retrieved from http://www.michigan.gov/documents/mde/PC_Guide_Final_5_12_09_ 277958_7.pdf 
Raywid, A. (1998). The journey of the alternative schools movement: Where it's been and where it's going. High School Magazine, 6(2), 10-14.

ResearchWare (2007). HyperResearch: Qualitative analysis tool (Version 2.8). Randolph, MA: ResearchWare, Inc.

Strauss, A., \& Corbin, J. (1998). Basics of qualitative research: Techniques and procedures for developing grounded theory. Thousand Oaks, CA: Sage.

Tufly, C. (2001). An alternative to failure. Principal Leadership, 2, 39-41.

Wilkins, J. (2008). School characteristics that influence student attendance: Experiences of students in a school avoidance program. The High School Journal, 91(3), 1224. 